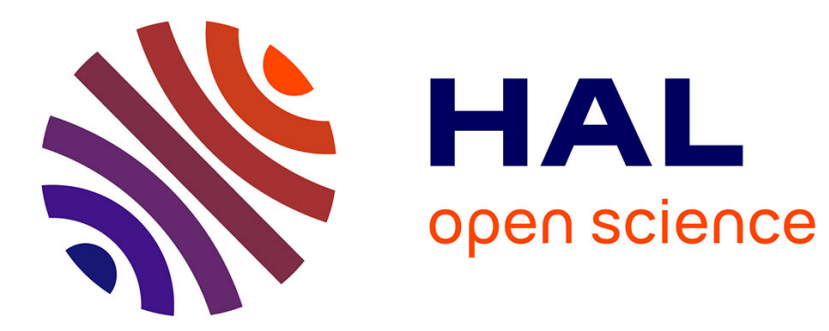

\title{
Development of a Part Criticality Index in Inventory Management
}

Clint Saidy, Liudas Panavas, Ramy Harik, Abdel-Moez Bayoumi, Joseph Khoury

\section{- To cite this version:}

Clint Saidy, Liudas Panavas, Ramy Harik, Abdel-Moez Bayoumi, Joseph Khoury. Development of a Part Criticality Index in Inventory Management. 14th IFIP International Conference on Product Lifecycle Management (PLM), Jul 2017, Seville, Spain. pp.184-195, 10.1007/978-3-319-72905-3_17 . hal-01764198

\section{HAL Id: hal-01764198 \\ https://hal.inria.fr/hal-01764198}

Submitted on 11 Apr 2018

HAL is a multi-disciplinary open access archive for the deposit and dissemination of scientific research documents, whether they are published or not. The documents may come from teaching and research institutions in France or abroad, or from public or private research centers.
L'archive ouverte pluridisciplinaire HAL, est destinée au dépôt et à la diffusion de documents scientifiques de niveau recherche, publiés ou non, émanant des établissements d'enseignement et de recherche français ou étrangers, des laboratoires publics ou privés. 


\title{
Development of a Part Criticality Index in Inventory Management
}

\author{
Clint Saidy ${ }^{1}$, Liudas Panavas ${ }^{2}$, Ramy Harik ${ }^{3}$, Abdel-Moez Bayoumi ${ }^{4}$, Joseph Khoury ${ }^{5}$ \\ ${ }^{1}$ Department of Mechanical Engineering, College of Engineering and Computing, University of \\ South Carolina, Columbia, South Carolina, USA \\ csaidy@email.sc.edu \\ ${ }^{2}$ Department of Mechanical Engineering, College of Engineering and Computing, University of \\ South Carolina, Columbia, South Carolina, USA \\ lpanavas@email.sc.edu \\ ${ }^{3}$ Department of Mechanical Engineering, College of Engineering and Computing, University of \\ South Carolina, Columbia, South Carolina, USA \\ harik@cec.sc.edu \\ ${ }^{4}$ Department of Mechanical Engineering, College of Engineering and Computing, University of \\ South Carolina, Columbia, South Carolina, USA \\ bayoumi@cec.sc.edu \\ ${ }^{5}$ Methode Electronics Middle East S.A.L \\ Mega Mall, Lower Level, Damascus Road, Furn El Chebbak, Beirut, Lebanon \\ Joseph.khoury@methodemideast.com
}

\begin{abstract}
Due to uncertainties in demand, some parts might go out of stock during the manufacturing process leading to backorders if an outof-stock part is critical. In order to reduce additional cost it is important to optimize restocking processes. To do so, the concept of Part Criticality is used to rank and prioritize parts involved in the production of different products. In this paper, we develop an algorithm to get the Compound Global Index which represents the part criticality.
\end{abstract}

Keywords. Supply Chain, Inventory Control, Uncertainty, Criticality.

\section{$1 \quad$ Introduction}

As businesses grow in size, inventory management analysis is becoming more important to increase efficiency and profits by reducing backorders and surpluses. Part of this change is a result of limited in house production of parts and a focus on final 
assembly, which creates a need to evaluate part criticality in the supply chain. The two fundamental problems that arise from a poor supply chain are a large backlog and surplus. The percentage of items backordered and the number of backorder days are important measures of the quality of a company's customer service and the effectiveness of its inventory management. On the other hand, if the business has an inventory surplus it will incur costs to store, track and insure inventory. Therefore, creating an inventory management system that ranks part criticality based on their creation of backorders and surpluses can create significant financial and customer service improvements for a business.

Two common inventory-management strategies are the just-in-time (JIT) method, where companies plan to receive items as they are needed rather than maintaining high inventory levels, and materials requirement planning (MRP), which schedules material deliveries based on sales forecasts. JIT means that manufacturers and retailers keep only what they need to produce and sell products in inventory, which reduces storage and insurance costs, as well as the cost of liquidating or discarding unused, unwanted inventory. To balance this style of inventory management, manufacturers and retailers must work together to monitor the availability of resources on the manufacturer's end and consumer demand on the retailer's. The MRP inventory management method is salesforecast dependent. This means that manufacturers must have accurate sales records to enable accurate planning of inventory needs and to communicate those needs with materials suppliers in a timely manner. These methods are geared towards supply chain management and are concerned with when certain products are to be ordered but do not incorporate in what order and whether they should be ordered. Overall, these methods view all parts as having equal importance and miss the part criticality tier that helps account for imperfections and differentiation between different parts that affect production time.

To achieve a balance between efficient customer service and low inventory cost, an optimization model should be set in place that finds a part that is most critical amongst the bills of material. Companies cannot spread their recourses equally amongst all the products and inventory management. By defining the most important parts companies will be able to more efficiently delegate their resources. In order to do this, an algorithm will be created using different components of existing part criticality models found through a literature review. Then the part criticality index will be generated in order to target critical parts on the inventory floor and will be simulated through randomly generated number tests. Finally, the system will be placed in a real world application to test its effectiveness.

\section{$2 \quad$ Literature Review}

As business and production facilities grow in size and complexity, inventory and supply chain management have grown increasingly important to gain an upper edge. Today's environment is no longer brand vs brand but instead involves entire supply chains 
[4]. A large part of this supply chain is material requirement planning and safety stock decisions. With the cost of holding inventory as high as $40 \%$ of the inventory value, it is important to maintain the optimal amount [8].

Modeling and determining the optimal amount of inventory depends on several factors. Depending on the company size, either a single or a multi-echelon system should be put in place. If the model represents a single entity, such as a warehouse, a single echelon model is used. Multi-echelon, composed of many single-echelon systems, models are used most often due to current companies size [3]. Finally, event occurrences can be assigned numbers, deterministic or stochastic, when creating inventory models. All these variables create a variety of inventory management policies.

The first part criticality inventory system investigated is the spare parts theory, which involves the assignment of criticality to the parts that make up the manufacturing equipment. Due to the high uncertainty of the requirement of the spare parts and small amount of suppliers, spare parts are inherently difficult to manage. This generally causes a large amount of overstocking [7]. In order to deal with these issues, spare parts are generally put into categories in order help create proper stocking. Drekker began this by allowing equipment criticality to determine the stock of spare parts by assigning each piece of equipment a status of either "critical and non-critical" [2].

In order to determine the optimal order quantity and reorder point for aircraft spare parts, Aisyati et al. [1] used a continuous review model. The suggested model resulted in smaller total cost compared with existing policy. An ABC classification system was used to categorize the parts based on their dollar contribution. Focus was on class A and B which commonly known as important classes. The result from the research indicates that the continuous review policy gives a significant amount of saving compared to the pre-existing policy. Finally, in order to expand on the ABC model, Stoll [9] used a three dimensional approach allowing for the predictability of demand and importance of the part to be calculated in. The spare part inventory theories lay the groundwork for determining the criticality of different parts of a production facility.

Another way to examine the importance of a part is to investigate the intricate web of the interactions among the units of related systems. One of the most successful recent approaches to capturing the fundamental features of the structure and dynamics of complex systems has been the investigation of the networks associated with the units (nodes) together with their relations (edges). Mones et al. [6] developed an approach and proposed a measure capable of capturing the essential features of the structure and the degree of hierarchy in a complex network. The measure introduced is based on a generalization of the m-reach centrality, which is first extending to directed/partially directed graphs. Then, a global reaching centrality (GRC) was defined, which is the difference between the maximum and the average value of the generalized reach 
centralities over the network. Results for real networks show that the hierarchy measure is related to the controllability of the given system.

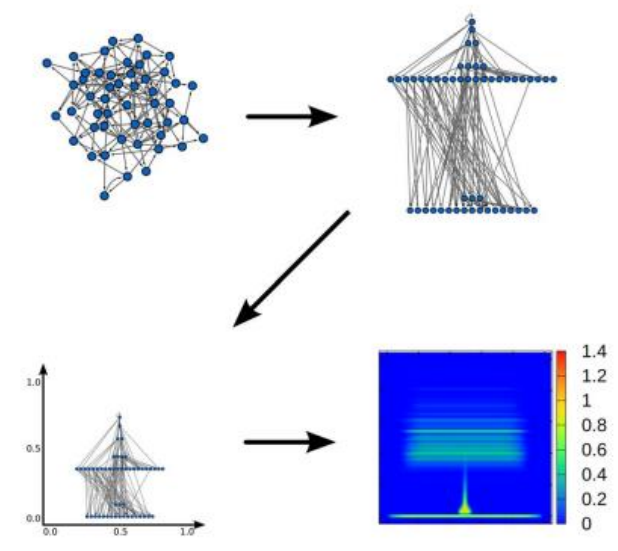

Fig. 1. Diagram illustrating the process of visualizing an ensemble of networks.(Mones et al., 2012)

Manzini et al [5] uses the method of nodes and edges to create a system to deal with manufacturing-to-order and assembly-to-order processes. Since each product is unique there is no large part inventory to pick from. To formalize the utilization of the part in the production, Manzini lets the source node be when the part is introduced and the sink node be the milestone before the production operation requiring the component. Then to evaluate the criticality of the part, Manzini finds the overlap of the probability that the component is needed in the production operation and the probability that component has not arrived. An overlap of these provides a risk that determines the criticality of the part. The system of edges and nodes works well in production lines because of the step-by-step nature of manufacturing facilities.

\section{Defining the Part Criticality Index}

The solution employed in this paper focuses on the idea on part Criticality in Inventory Management. This idea stems from:

- The spare parts inventory management technique where equipment spare parts are assigned a value due to their criticalness to the production line [2].

- The system of nodes and edges Mones et al. put forward to describe the fundamental features and hierarchies of a structure and dynamics of complex systems [6]. 


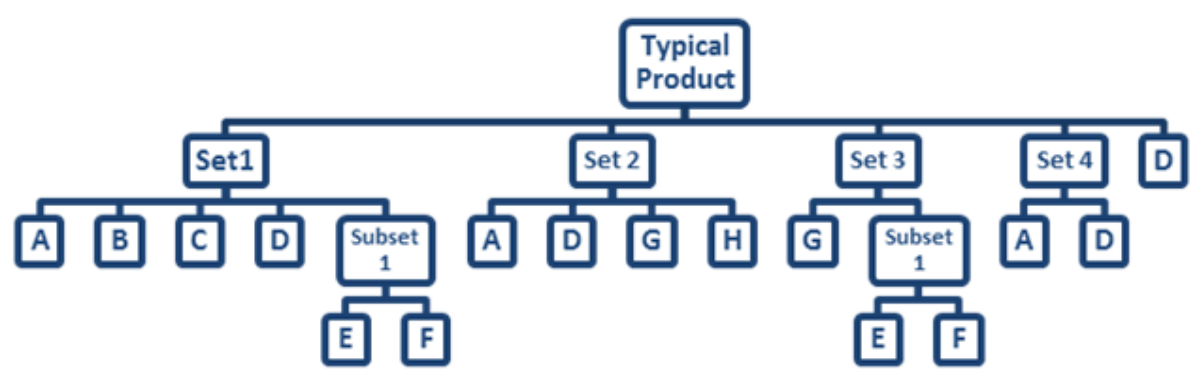

Fig. 2. Typical Product

Combining these two systems gave a unique approach to determining the part criticality. The spare parts inventory management system introduced the concept of backlogs and order demand to part criticality while the system of nodes and edges allowed for the complex system of a product and production line to be simplified and quantified.

The system of nodes and edges can be applied to a production line if the nodes are looked at as parts and edges being the assembly links. If a part is out of stock, this cuts off connections not allowing the production to flow through the map to the final assembly. The most critical parts of a product then become the parts with the most connections due to their ability to cut off more of the production line and are therefore given preference in stocking systems. The spare part inventory technique was used to rank the product criticality by including the demand and backlog. This way the most important part could be found by combining the most important parts and products of a production line. This will helps envision the bigger supply chain later in order tackle criticality not only on the factory floor but by reaching suppliers and enhancing the cooperation between all the supply chain entities. A general approach for the creation of each factor in the methodology is listed below followed by a more detailed approach. 


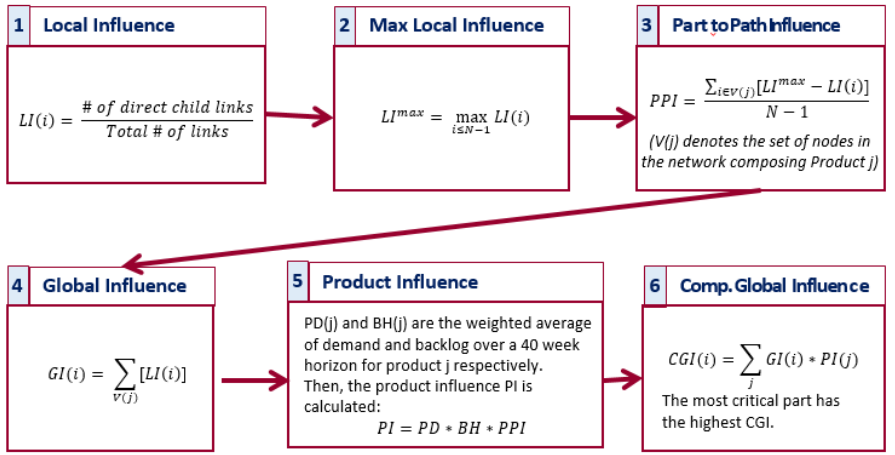

Fig. 3. Path to find part criticality

\subsection{Local Influence}

The first step is to define the local influence of a certain node i (nodes in this case represent parts, sub-parts, and the final product) in an unweighted directed graph. The studied network is a directed network since only parts lead to sub-parts which lead to final product and not the other way around. The local influence, LI(i), is defined as the proportion of all nodes in the graph that can be reached from node i via incoming edges to i.

$$
L I(i)=\frac{\# \text { of direct child links }}{\text { Total \# of links }}
$$

A child link is a link that connects the parent node to the child node i.

\subsection{Maximum Local Influence}

After calculating local influence at all nodes, we designate $\mathrm{LI}^{\max }$ as the highest Local Influence. $\mathrm{LI}^{\max }$ will be used in the following step in order to normalize the Local Influence to compare LI of a certain part between different products.

$$
L I^{\max }=\max _{i \leq N-1} L I(i)
$$

\subsection{Part to Product Influence}

Thus, we can calculate the Part to Product Influence (PPI):

$$
P P I=\frac{\sum_{i \in V(j)}\left[L I^{\max }-L I(i)\right]}{N-1}
$$

Note that $V(j)$ denotes the set of nodes in the network composing Product $j$. 
Calculating the PPI allows us compare the influence of the parts on different products.

\subsection{Global Influence}

The Global Influence of a Part in a Product can be calculated as follows:

$$
G I(i)=\sum_{V(j)}[L I(i)]
$$

In other words GI(i) represents the weight of each part in a product, bigger GI(i) shows that part $\mathrm{i}$ is a major component of the product.

\subsection{Product Influence and Backlog History}

Calculate Product Influence and Backlog History of each product. This is an important criterion to relate each product to the larger picture of the entire production facility.

a. $\quad \mathrm{PD}(\mathrm{j})$ is the weighted average of Demand over a 40 week horizon for product $\mathrm{j}$.

b. $\mathrm{BH}(\mathrm{j})$ is the weighted average backlog over a 40 week horizon for product $\mathrm{j}$.

c. Calculate the product Index PI which is the product of PPI, PD, and BH.

\subsection{Compound Global Index}

The last step is to find the Compound Global Index (CGI) that represents the part criticality among all products. The CGI brings together the most important parts and products to find the most critical parts to the production line. To calculate CGI for each part, we use the following equation representing the sum-product of parts Global Influence in each product and the Product Influence:

$$
C G I(i)=\sum_{j} G I(i) * P I(j)
$$

The higher the parts CGI the more critical it is.

\section{$4 \quad$ Inventory Model}

\subsection{Products}

Six fictional products where created in order to apply the above-mentioned algorithm. Each product consists of a set of parts, subsets, and sets. Note that subsets are subassemblies of parts, and sets are subassemblies of parts and subsets. Creating multiple 
products helps create a more realistic representation of a large final assembly production facility.

\subsection{Supply and Demand}

In this model, both supply and demand are set as constant stochastic variables. The distribution used is the uniform distribution. Furthermore, a finite planning horizon of 40 weeks is used.

\subsection{Inventory and Backlog}

In order to perform accurate long run simulations a model was created to help us simulate a realistic scenario where inventory is not scrapped from period to another and unmet demand is met in the upcoming periods. In create this model inventory from one period to another is kept and unmet demand from one period to another is backlogged.

Inventory, $\mathrm{I}(\mathrm{n})$, and shortage, $\mathrm{S}(\mathrm{n})$, for a typical period $\mathrm{n}$ is calculated as follows:

$$
\begin{gathered}
I(n)=I(n-1)+\operatorname{Max}[Q(n)-D(n), 0] \\
I(0)=0 \\
S(n)=S(n-1)+\operatorname{Max}[D(n)-Q(n), 0] \\
S(0)=0
\end{gathered}
$$

Note that $\mathrm{D}(\mathrm{n})$ and $\mathrm{Q}(\mathrm{n})$ represent Demand and Supply during a period $\mathrm{n}$ respectively.

\section{$5 \quad$ Discussion of Results}

\subsection{Primitive Model}

A first model was developed with the following assumptions: surplus inventory from one term to another is scrapped and backlog is not allowed, i.e., unmet demand during a certain period is disregarded in the next period. For this model, all random simulation led to same result, the same part was found to be critical. But, this model is not logical since inventory can be kept from one period to another and unmet demand is usually met in the upcoming periods. Hence, a more realistic model was developed in order to take into consideration surplus inventory and backlog. The integration of these parameters was already discussed in section 3.3.

\subsection{Short Run Results}

After embedding surplus inventory and backlog in the model, short run simulation were run based on a 40-week horizon, and then long run results were calculated. The long run results were based on a series of 10 short runs. 
Many short run simulations were run, and every time a different part was found to be critical. This randomization was boosted by the introduction of the 2 assumptions discussed above. 5 runs are documented in the table below. For the first run, part $\mathrm{N}$ was the most critical, for the second and fourth run, part D was the most critical, and followed by part A. And for the third and fifth runs, Part A was the most critical followed by part D. this can be explained by the probabilistic distributions used to represent both supply and demand and their involvement in the calculation of the Product Index PI (section 3.5). The short run simulations did not provide definitive results so the long-term model was though of and put in place to see if a more consistent results could be obtained.

Table 1. Global Compound Index Calculation

\begin{tabular}{|c|c|c|c|c|c|c|}
\hline Part & Run 1 & Run 2 & Run 3 & Run 4 & Run 5 & Long Run \\
\hline Set 1 & 0.00377075 & 0.01551306 & 0.00278513 & 0.01262664 & 0.00974517 & 0.00762882 \\
\hline Set 2 & 0.01476691 & 0.00870292 & 0.00638843 & 0.01012183 & 0.01360051 & 0.01741808 \\
\hline Set 6 & 0.0147669 & 0.0004902 & 0.00369514 & 0 & 0.01181458 & 0.00638000 \\
\hline Set 7 & 0.0147669 & 0.0004902 & 0.00369514 & 0 & 0.01181458 & 0.00638000 \\
\hline Subset1 & 0.0037707 & 0.0155130 & 0.00547842 & 0.01473918 & 0.01065167 & 0.01095505 \\
\hline A & 0.0336402 & 0.0340810 & 0.02179057 & 0.03309916 & 0.03720555 & 0.04400146 \\
\hline B & 0.0037707 & 0.0237257 & 0.00278513 & 0.02063593 & 0.01062458 & 0.01534066 \\
\hline D & 0.0223084 & 0.0479417 & 0.01465198 & 0.04549695 & 0.03487678 & 0.04371381 \\
\hline E & 0.0037707 & 0.0155130 & 0.00547842 & 0.01473918 & 0.01065167 & 0.01095505 \\
\hline F & 0.0076533 & 0.0314087 & 0.00763605 & 0.02532956 & 0.01957679 & 0.01576854 \\
\hline G & 0.0147669 & 0.0087029 & 0.00908172 & 0.01223438 & 0.01450702 & 0.02074432 \\
\hline H & 0.0148787 & 0.0090855 & 0.00845421 & 0.01019812 & 0.01368696 & 0.01792899 \\
\hline J & 0.0147669 & 0.0087029 & 0.00369514 & 0.00800929 & 0.01269400 & 0.01409185 \\
\hline L & 0.0148787 & 0.0008728 & 0.00576092 & $7.63 \mathrm{E}-05$ & 0.01190104 & 0.00689090 \\
\hline M & 0.0334164 & 0.0168612 & 0.00954791 & 0.0105903 & 0.0325542 & 0.01757349 \\
\hline N & 0.0443007 & 0.0014706 & 0.01108543 & 0 & 0.03544376 & 0.019140008 \\
\hline O & 0.0223084 & 0.03151636 & 0.00387883 & 0.02102819 & 0.02949191 & 0.01498517 \\
\hline
\end{tabular}

\subsection{Long Run Results}

In order to develop the long run results, ten short run simulations were run and a weighted average of the CGI for every part was calculated. This procedure was repeated three times, and the same part was found to be critical. This shows that regardless of the variations on the short term, on the long term, the same part will be critical. Table 1 shows that the most critical part on the long run is A followed by the part D. The long run simulation amortized the effect of the stochastic distribution of the demand and supply leading to one part being critical on the long run.

\subsection{Pareto Analysis}


Ideally, managment wants to focus its attention on fixing the most important problems. But how do they decide which problems they need to deal with first? Pareto Analysis helps prioritize the most critical parts by finding the 20 percent of parts that generate 80 percent of the criticality.

In this simulation, 80 percent of the criticality is caused by more than 20 percent of the parts (figures 2 and 3), thus violating the 80/20 rule. Pareto charts are extremely useful for analyzing what problems need attention first because the taller bars on the chart, clearly illustrate which parts have the greatest cumulative effect on a given system.

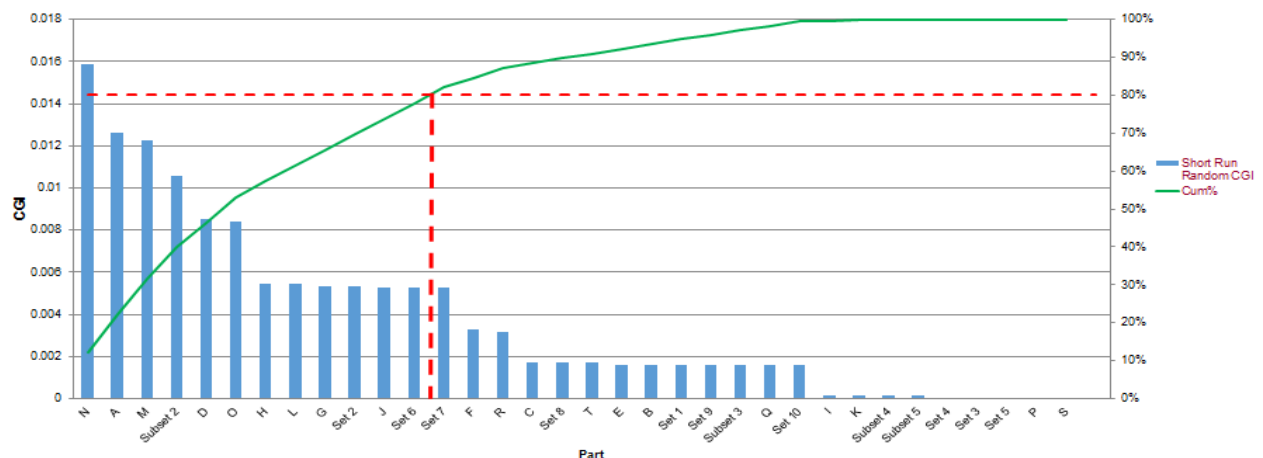

Fig. 4. Random Short Run Pareto Chart

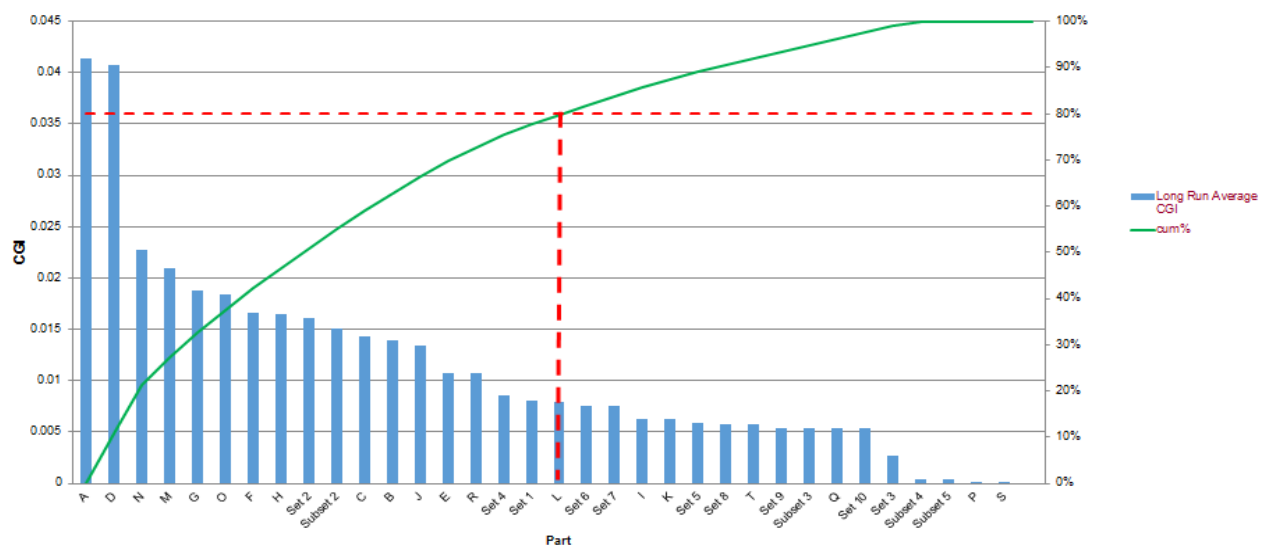

Fig. 5. Long Run Pareto Chart

\section{$6 \quad$ Industry Significance}

Our next step is to create a program that optimizes inventory management by identifying the criticality of parts to a company's production. The program will allow a 
company to insert data from their production line and the most important parts will then be determined using a part criticality algorithm. These parts will then be given priority in the pre-existing inventory management system.

The long-term goal for this project will be to create a wiki-like database for local manufacturers that can create parts used in the aerospace industry. Many large companies such as Boeing outsource many of the parts that go into their planes first from outside the USA and second from outside of South Carolina. Therefore, if a part is defective there are long shipping times and delays that may occur. Determining both the criticality of the parts used on the assembly line and the parts in the products delivered could help reduce these issues because local manufacturers could be identified in order to get the part quickly. This would be a part of the actions taken in order to help engage local suppliers in the advancement of the aerospace market in South Carolina. The figure below shows the breakdown of the Boeing 787 airplane along with the origin of each part.

The figure below shows the breakdown and origin of major parts of the Boeing 787 manufactured in Charleston, SC.

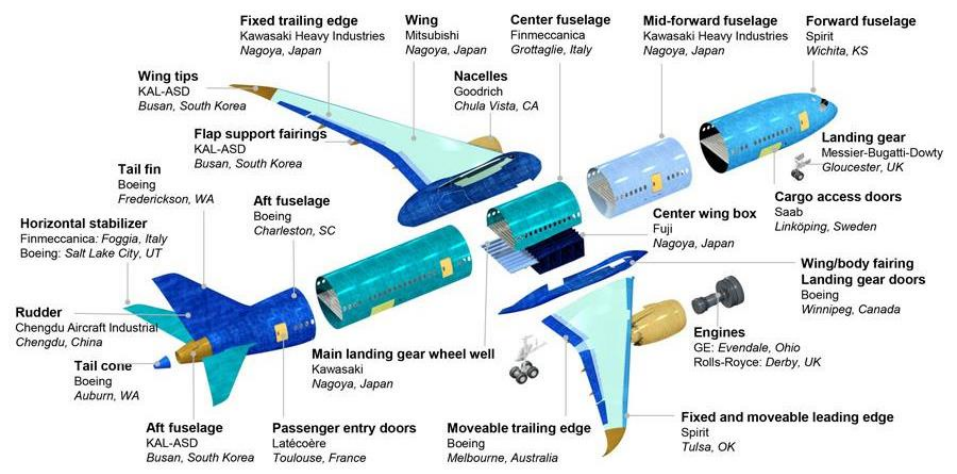

Copyright 02015 Boeing. All right reserved.

Fig. 6. Boeing 787 Breakdown $^{1}$

The below image shows the spread of first tier suppliers hired by Boeing.

\footnotetext{
${ }^{1}$ Boeing 787 Dreamliner structure: parts from around the globe. Retrieved May 10, 2017, from http://www.aeronewstv.com/en/industry/commercial-aviation/3707-boeing-787dreamliner-structure-parts-from-around-the-globe.html
} 


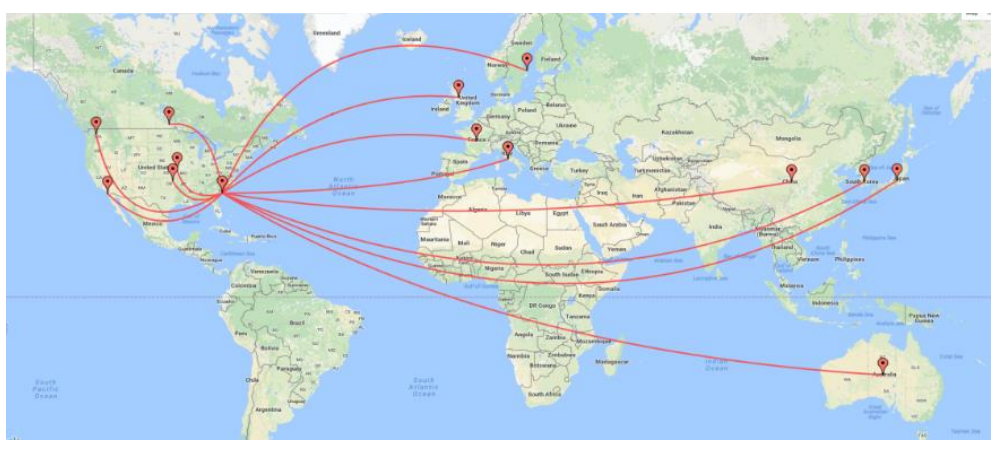

Fig. 7. Countries Supplying Parts for Boeing Charleston

Figure 6 shows the available aerospace related companies in South Carolina. These companies can be beneficial for Boeing since they are close to the plant in Charleston leading to easier cooperation and less variability.

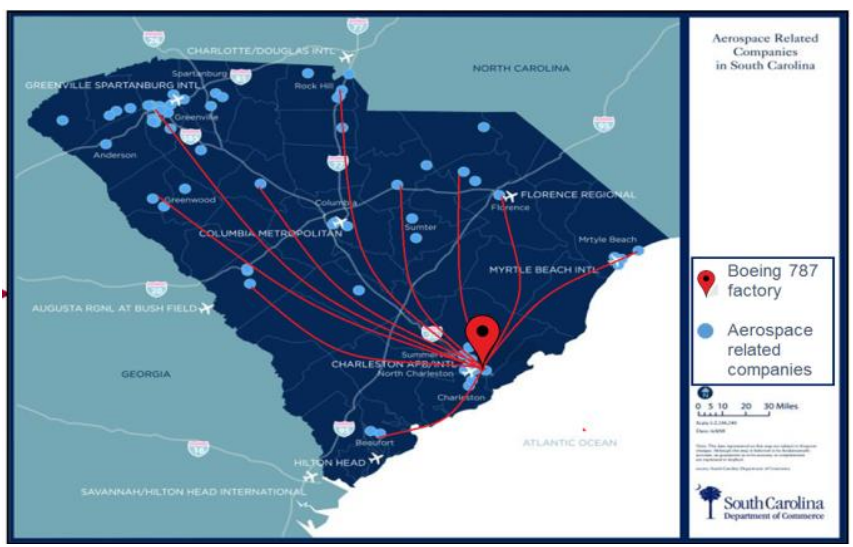

Fig. 8. Potential Aerospace Suppliers in South Carolina ${ }^{2}$

Our goal is to create a multi-echelon cooperative supply chain network within South Carolina in order to increase the involvement of local aerospace related companies in the manufacturing of the Dreamliner and hence decreasing the criticality among the parts since suppliers will be more within reach.

\section{$7 \quad$ Conclusion}

\footnotetext{
${ }^{2}$ South Carolina Department of Commerce
} 
In this paper, we determined the Part Criticality defined as Compound Global Index. This index defined part criticality by utilizing the interdependence of different parts as well as backorder and surplus quantities. A set of simple products having common parts was employed in order to validate the algorithm. Results showed that on the short term, criticality might vary form one term to another. This is mainly caused by the variability of demand and supply. Furthermore, this criticality was affected by the inventory policy set in place for this simulation.

A further step would be to simulate other inventory policies in order to study their effect on the part criticality. As for the long run results, it was realized that one part was the most critical. This short run/long run differentiation helps the management have a plan to tackle parts that are critical on the short term as well as creating long term improvement policies to decrease the long term part criticality.

\section{$8 \quad$ References}

1. Aisyati, A., Jauhari, W. A., Rosyidi, C. N. (2013). Determination Inventory Level for Aircraft Spare Parts Using Continuous Review Model. International Journal of Business Research and Management (IJBRM), Volume (4) : Issue (1) : 2013.

2. Dekker, R., Kleijn, M., \& Rooij, P. D. (1998). A spare parts stocking policy based on equipment criticality. International Journal of Production Economics, 56-57, 69-77. doi:10.1016/s0925-5273(97)00050-9

3. Hausman, W. H., \& Erkip, N. K. (1994). Multi-Echelon vs. Single-Echelon Inventory Control Policies for Low-Demand Items. Management Science, 40(5), 597-602. doi: $10.1287 / \mathrm{mnsc}$.40.5.597

4. Lambert, D. M., \& Cooper, M. C. (2000). Issues in Supply Chain Management. Industrial Marketing Management, 29(1), 65-83. doi:10.1016/s00198501(99)00113-3

5. Manzini, M., \& Urgo, M. (2015). Critical Components Evaluation in Manufacturing-To-Order Processes. Procedia CIRP, 37, 146-151. doi:10.1016/j.procir.2015.08.046

6. Mones, E., Vicsek, L., \& Vicsek, T. (2012). Hierarchy Measure for Complex Networks. PLoS ONE, 7(3). doi:10.1371/journal.pone.0033799

7. Roda, I., Macchi, M., Fumagalli, L., \& Viveros, P. (2014). A review of multicriteria classification of spare parts. Journal of Manufacturing Technology Management, 25(4), 528-549. doi:10.1108/jmtm-04-2013-0038

8. Sandvig, C. and Reistad, A. (2000), "Safety stock decision support tool", Production and Inventory Management Journal, Vol. 41 No. 4, pp. 7-10

9. Stoll, J., Kopf, R., Schneider, J., \& Lanza, G. (2015). Criticality analysis of spare parts management: a multi-criteria classification regarding a cross-plant central warehouse strategy. Production Engineering, 9(2), 225-235. doi:10.1007/s11740015-0602-2 